\title{
AMENDMENTS
}

\section{Author Correction: Near-future carbon dioxide levels alter fish behaviour by interfering with neurotransmitter function}

Göran E. Nilsson, Danielle L. Dixson, Paolo Domenici, Mark I. McCormick, Christina Sørensen, Sue-Ann Watson and

Philip L. Munday

Correction to: Nature Climate Change https://doi.org/10.1038/nclimate1352, published 15 January 2012.

In this Letter, the $N$ values presented in Figs. $2 \mathrm{a}$ and $2 \mathrm{~b}$ were mistakenly swapped: this did not affect the statistical outcomes or interpretation of the data. The corrected version of the figure is shown below; the original Letter has not been corrected.

Original

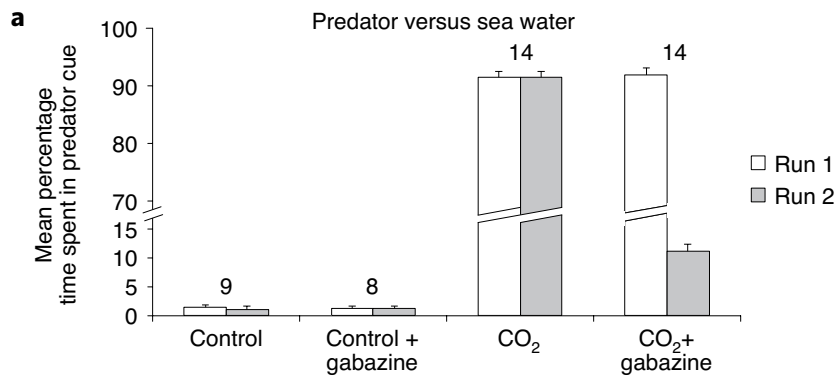

b

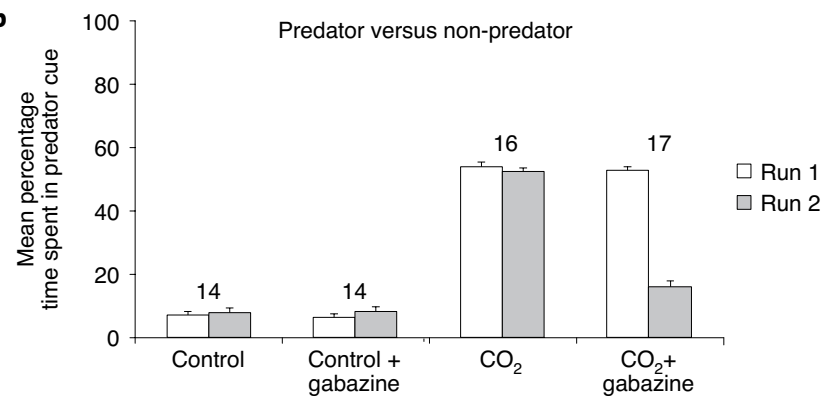

Corrected
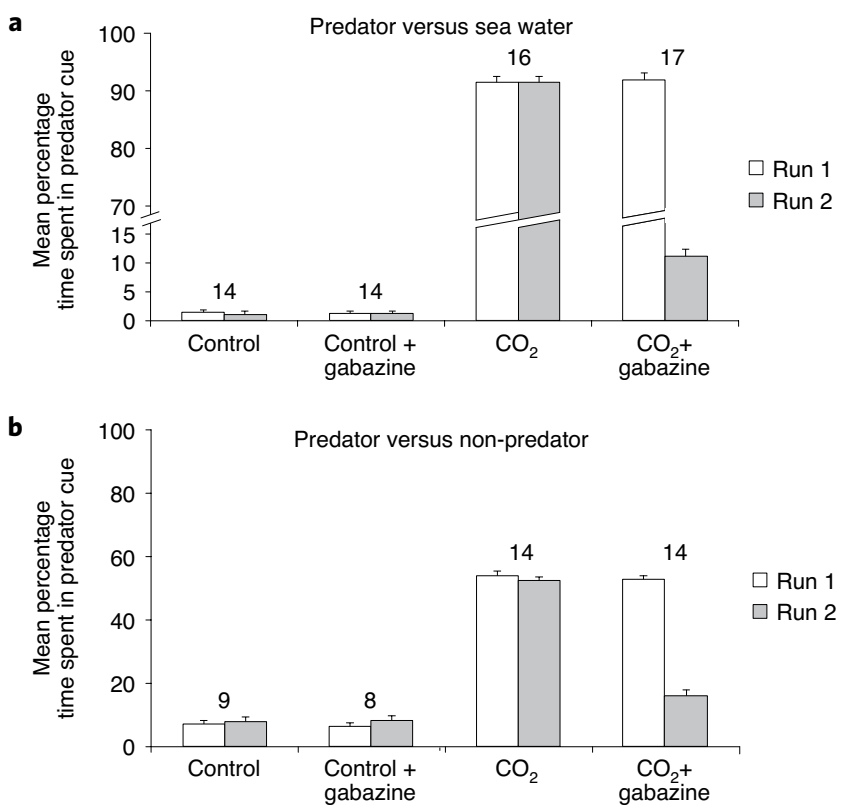

Fig. 2a,b | Original and Corrected.

Published online: 16 June 2020

https://doi.org/10.1038/s41558-020-0836-7

(c) The Author(s), under exclusive licence to Springer Nature Limited 2020 